\title{
Community-Clinical Partnership: Engaging health navigators to support refugees and non-refugee immigrants amidst the COVID-19 pandemic
}

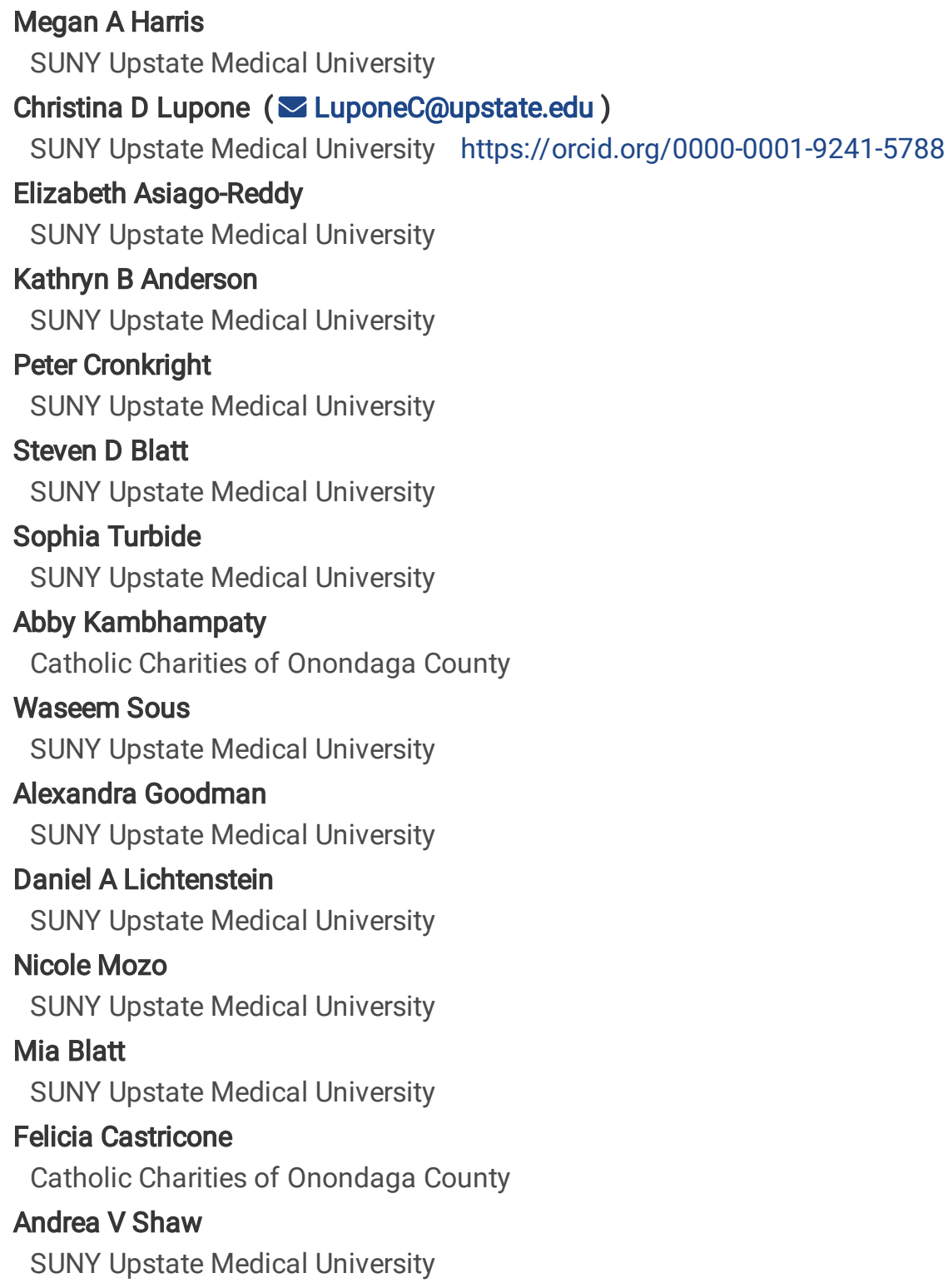




\section{Abstract}

Background: The COVID-19 pandemic has exacerbated health inequities in vulnerable populations. Linguistic and sociocultural barriers, misinformation, and mistrust of Western medicine hinder public health outreach to diverse refugee and non-refugee immigrant communities. SUNY Upstate Medical University partnered with local resettlement agencies and health navigators to expand outreach and screening to this hard-to-reach population.

Methods: Health navigators engaged participants for enrollment and screening. SARS-CoV2 status was assessed via RT-PCR of saliva swabs. Surveys captured COVID-19-related psychosocial behavioral insights.

Results: Over 9 weekly sessions, 603 individuals in 195 refugee/immigrant households from 27 countries of origin were screened. COVID-19 positivity rate was $2 \%$ for households and $0.2 \%$ amongst individuals. Surveys provided insight into households' concerns and health behaviors, and a space to reinforce protective behaviors and address misinformation and stigma.

Conclusions: During these unprecedented times, our interdisciplinary community-clinical partnership successfully implemented COVID-19 screening, outreach, and support to local refugees and non-refugee immigrants through trusted networks of culturally, socially, linguistically congruent health navigators.

\section{Background}

In the United States (U.S.), refugees and non-refugee immigrants face many barriers to optimal health and well-being [1-5]. All such barriers should be considered in the context of the turbulent healthcare and economic climate resulting from the COVID-19 pandemic, which has exacerbated health and socioeconomic inequities affecting minority populations [6-10]. As the U.S. continues experiencing a rising death toll and widened gaps in socioeconomic and health parameters due to COVID-19, the adverse impact on vulnerable refugee and non-refugee immigrant populations must be recognized and mitigated [6,7,10-12].

This year, the U.S. Centers for Disease Control and Prevention (CDC) released a call to action addressing the vulnerability of the refugee population amidst the pandemic and recommended a list of risk-mitigating actions [11]. One recommendation is to collect social, demographic, and clinical characteristics of refugees who have COVID-19 in order to improve understanding of "cultural, economic, social, and health factors among refugees that may have implications for them during the COVID-19 pandemic," and to inform culturally appropriate strategies for communicating tailored prevention and control messages. Another CDC recommendation is to learn about the impact of COVID-19 via frequent communications with partners that assist refugees (i.e., resettlement agencies, health navigators, clinicians) [11].

In Syracuse, New York (NY), local stakeholders-healthcare providers, resettlement organizations, and the health departmentsimilarly recognized a need to improve public health communication, outreach, support, and access to COVID-19 testing for the local refugee and non-refugee immigrant community.

\section{Local Context}

The city of Syracuse, in Onondaga County of Central NY, embraces a diverse refugee and non-refugee immigrant population. In the past 10 years, Syracuse has welcomed over 7,000 refugees from over 25 countries, and currently $13.3 \%$ of the city's residents are foreign born $[13,14]$. Despite its rich background in resettlement, myriad barriers impact the Syracuse new American population as the city grapples with persistent health and socioeconomic inequities embedded in a history of redlining and segregation [15]. Concentrated poverty among minority residents is among the highest in the nation and adverse health outcomes are well documented [15-17].

In Syracuse, ZIP codes most heavily populated by refugees show $>50 \%$ of the confirmed COVID cases [18]. Numerous local employers of workers with limited-English proficiency (LEP) experienced outbreaks [19,20]. Initial efforts to increase testing at mobile sites in high impact areas saw low turnout from LEP individuals. Refugee resettlement agencies reported many clients feared the discomfort of nasopharyngeal swabs, faced stigma around both the act of testing and the potential positive test, and circulated COVID-19 related "myths" [21,22]. 
Two resettlement agencies in Syracuse have long provided a robust support structure for new Americans. Upon arrival of COVID19 , safe and early outreach to vulnerable populations was prioritized [22]. Between the agencies, there are eight community health navigators, all former refugees themselves, who speak over 20 languages fluently and supplement the work of case managers to routinely connect and extend services to approximately 400 refugee households. They have been integral to COVID-19 relatedoutreach efforts.

The health navigators we work with are synonymous to community health workers (CHWs), and play an integral role at the intersection of community and healthcare. Health navigator investment cultivates community trust and essential linkages that address social determinants of health [23-26]. Healthcare institutions in New York City, heavily impacted early on in the pandemic, have highlighted local CHWs as frontline team members who have adapted work flows to address social factors influencing disparities in COVID-19 infections and outcomes [26].

Facilitated through a community-clinical partnership between refugee resettlement agencies and SUNY Upstate Medical University, the aims of this study were to implement non-invasive COVID-19 screening to refugee and non-refugee immigrant households in Syracuse, NY; to assess household demographics and COVID-19-related knowledge, risk perception, and current behaviors with the intent of informing ongoing public health education and outreach; and to provide support and linkages to clinical care. Findings from 3 months of COVID-19 surveillance, household surveys, and outreach are presented herein.

\section{Methods}

\section{Outreach, Recruitment, Enrollment}

Study enrollment occurred July $14^{\text {th }}-$ September $15^{\text {th }}, 2020$ during weekly sessions from 2-8pm. Participant recruitment was spearheaded by health navigators who leveraged their trusted and engaged community positions during ongoing public health education and outreach efforts. As households enrolled, secondary spread of information occurred through social networks and ethnic and religious community leaders. Health navigators and community leaders targeted outreach to population subsets deemed high risk based on prior cases, reported fears, or demonstrated reluctance to obtain screening. Inclusion criteria included refugee and nonrefugee immigrants currently residing in Syracuse, NY. There were no age restrictions. Individuals reporting active symptoms suggestive of COVID-19 infection were assisted to contact their physician and forgo surveillance.

The community-clinical partnership team consisted of clinicians, nurses, public health/ethics researchers, health navigators, case managers, community leaders, and program directors. This interdisciplinary team organized and supported weekly screening efforts at an accessible community center operated by Catholic Charities (locally known as "CYO"). For decades, CYO has served as a hub for refugee support services (language classes, citizenship classes, employment assistance, housing support, etc.), cultural exchange, and relationship building.

\section{Screening for COVID-19}

Non-invasive, self-administered saliva swabs (DNA Genotek) were utilized for COVID-19 screening [27-29]. Samples were stored at room temperature before transport to SUNY Molecular Analysis Core Facility for SARS-CoV-2 viral RNA detection via real-time PCR analysis.

Health navigators or case managers assisted with result delivery and translation, which occurred within 48 hours of swab collection via participants' preferred language. The principal investigator $(\mathrm{Pl})$, with translation support from health navigators, delivered all positive COVID-19 results to households and arranged confirmatory nasopharyngeal testing at a University-supported drive-through site. The PI directs the refugee primary care clinic at Upstate and facilitated follow-up and support for all confirmed cases via the COVID Transitions Clinic (a virtual, multidisciplinary team holistically supporting patients with COVID-19). 
Household data and survey responses for every enrolled household, and demographic information for every enrolled individual, were obtained by trained health navigators, case managers, or study personnel with translation assistance. Surveys captured information about COVID-19 related household behaviors, risk perceptions, knowledge, and preferred means of health-related communication. Many questions were open-ended, with responses later coded by trained study personnel. Data and information initially recorded on paper forms were subsequently transferred to electronic versions in REDCap software by trained study personnel. REDCap is a secure, HIPAA-compliant web application used extensively at SUNY for data storage and management. All paper documents were maintained in a secure location. Descriptive summary measures were calculated and displayed via use of Microsoft Excel (version 16.39) and GraphPad prism (version 8.4.2).

\section{Ethics approval}

This study was reviewed by the SUNY Institutional Review Board (IRB) (Project 1607447-2) and approved by Western IRB (Study Number 1284593). Informed consent was verbally translated and completed for all participating individuals, with additional informed assent for participants age 7-17. Participants retained written copies of consent forms in their preferred language.

\section{Results}

Enrollment began July $14^{\text {th }}, 2020$ and 195 households presented for participation over 9 weekly enrollment dates. Of the over 860 individuals comprised by these households, 603 presented for enrollment/screening.

\section{Screening Results}

Of 195 households, 4 screened positive for COVID-19 via saliva PCR, for a household positivity rate of $2 \%$. Of these, 3 households received follow-up nasopharyngeal swab testing at Upstate, and one individual was confirmed positive, for an overall individual test positivity rate of $0.2 \%$. This individual lived in an 11-person household with 2 family members participating in essential work outside the home.

\section{Sociodemographic Information}

Household demographics (Figure1)

Household sizes ranged 1 to 14 people, with a median size of $5(\mathrm{IQR}=3)$. Twenty-seven countries of origin and 22 primary spoken languages in the home were reported.). The most frequently reported primary spoken language in the home was Swahili (23.6\%), and the most frequently reported country of origin was Burma (18.5\%).

\section{Individual demographics (Table 1, Figures 2 and 3)}

The majority of participants (77\%) arrived in the U.S. within the past 5 years. Arrival years ranged from $1982-2020$, with 2016 as the most frequently reported (22.6\%). Sixty-four (10.1\%) were children born in the U.S. into refugee or non-refugee immigrant households. The cohort was $55.2 \%$ female with ages ranging 3 months to 85 years, and a median of 17 years $(I Q R=26.7)$. Table 1 displays educational attainment, employment status, and other individual-level sociodemographic data.

Essential workers comprised at least $42.9 \%$ of those that reported currently working. Though $16.2 \%$ did not report their occupation, common occupations of those that did included factory work (14.3\%), healthcare services (12.4\%), essential cleaning services (7.6\%), grocery/other service industry (5.7\%) and farming (4.8\%). Of 105 individuals that reported working, 61 provided information 
on frequency of mask-wearing at work, of which 85\% reported "always" and 8.2\% reported "almost always." Of 45 responses, 36 (80\%) reported that masks are provided by their place of work.

Of the 15 individuals that reported furlough/temporary leave, 9 (60.0\%) reported it was due to COVID-19, 4 (26.7\%) reported it was not, and 2 (13.3\%) did not provide a response. Of the 126 individuals that reported unemployment, 68 provided responses to whether they were working previously, of which 29 (42.6\%) reported "yes." Of these individuals, 25 provided responses to "why and when" they lost work; 13 (52.0\%) of them reported they lost work either after February 2020 or due to COVID-19.

\section{Survey Findings}

Risk perceptions (Table 2)

Twenty-seven (14.7\%) respondents perceived their household as high risk for COVID-19, with the most commonly reported rationale (open-ended) coded as, "household member(s) work outside the home" (37.0\%) and "pre-existing condition in self or household member" (18.5\%). Local places perceived as high risk for COVID-19 included grocery store/shopping centers (51.6\%), work (16.5\%), and hospitals or clinics (12.2\%).

Household Behaviors and Activities (Table 3)

Increased hand-washing/sanitizing (44.7\%), mask-wearing (39.4\%), and increased cleaning of surfaces (29.3\%) were the most commonly reported open-ended responses regarding household precautions during the pandemic. A majority reported all household members "always" wearing masks in public (86.9\%) and social distancing outside the home (59.7\%).

\section{COVID-19 related concerns (Figure 4)}

For all inquiries of concern in the context of COVID-19 - on a scale of 1-5 with 5 being "very concerned" and 1 being "not at all concerned"-the most frequently provided response was "very concerned." Household representatives provided it $33.8 \%$ of the time regarding concern for overall household health, $30.8 \%$ for household emotional health, $35.9 \%$ for their children's education, $34.4 \%$ for household finances, $32.8 \%$ for impact in local community, and $38.3 \%$ for impact in country of origin.

\section{Health communications (Table 4)}

The most frequently reported open-ended responses for how households $(\mathrm{N}=106)$ normally get their health information were news outlets (42.5\%) and social media (36.8\%). The most frequently reported open-ended responses for who they trust most when it comes to information about COVID-19 were doctors (generally or "my doctors/doctor's office") (49.1\%), and community-based sources (CYO or case managers/health navigators) $(23.6 \%)$.

\section{Declined participation}

Study personnel anecdotally observed the following reasons (not all-inclusive) for declined participation: having general mistrust of the health system, believing COVID-19 is fake or saliva swabs might be contaminated with coronavirus, having had a test in the past, being asymptomatic, lacking interest due to absence of a cure, and fearing the consequences of potential positive results such as quarantine and loss of income.

\section{Discussion}


As the global death toll of COVID-19 continues to rise, so grows the importance of mitigating its collateral effects on health equity. Of concern are refugee and non-refugee immigrant communities already facing myriad social, economic and health disparities. However, devising and implementing COVID-19 public health messaging, education, and disease surveillance strategies for multicultural and multilingual communities with varied backgrounds is complex. To develop sustainable and contextually-relevant solutions, close engagement with and empowerment of the local community is essential.

Resettlement agencies employing socially, linguistically, and culturally congruent health navigators joined forces with local university health providers to form a community-clinical partnership. This enabled 195 diverse refugee and non-refugee immigrant households to screen for COVID-19 and engage in dialogue that provided insight into community mindset and behaviors in the context of the pandemic. The benefits have been multifold.

\section{Prevalence of COVID-19}

This study found a $0.2 \%$ test positivity rate amongst local asymptomatic refugees and non-refugee immigrants at a time when the county test positivity rate was $0.8-1.2 \%$ [30]. This was an encouraging finding, given higher rates of infection in minority communities cited across the U.S. In July, a similar refugee population was screened in the nearby city of Utica whereby 650 individuals showed an $8 \%$ positivity rate in the context of an overall county positivity rate of $1.2 \%$ [19].

A number of factors may have contributed to the relatively low COVID-19 positivity rate observed in this study cohort. When the study began in mid-July of 2020, the local community was seeing a significant decline in COVID-19 cases-schools had not yet reopened in person learning and social gatherings were limited-and it is possible that our observations are reflective of that. Additionally, the study may have captured a lower risk subpopulation within the target population due to screening of mainly asymptomatic participants, the voluntary nature of participation, and high rate of high-risk employment in the population that may have logistically prohibited participation. The study team attempted to minimize such influences through flexible screening times and targeted recruitment efforts. Notably, low positivity rates might also be attributed, in part, to supportive community leaders and health navigators that have focused on disseminating preventative public health messaging since the pandemic's start [22].

\section{Data informed outreach \& education}

Targeted outreach facilitated efforts to capture a cohort reflective of the greater Syracuse refugee and non-refugee immigrant population. For example, upon initial demographic review (weeks 1-3), subjects originating from Syria, Iran, Iraq, Somalia, and Yemen were notably under-represented when compared to the greater Syracuse population [31,32]. All 5 countries received increased study representation after health navigators began targeted recruitment efforts. Ultimately, the study population comprised individuals of varied age, country of origin, primary spoken language, education, and employment background. Though participation was welcomed to all Syracuse refugee and non-refugee immigrant residents, targeted recruitment helped ensure inclusion of a diversity of ethnicity, background and experience - facilitating cross-culturally-informed education.

Most study participants reported activities and behaviors well-aligned with current public health recommendations during the pandemic, such as mask-wearing outside the home, physical distancing, and hand-washing/sanitizing. However, the prevalence of COVID-19 related myths uncovered by local resettlement agencies, qualitative feedback from health navigators as to why clients have refused study participation, and other survey findings highlight an ongoing need for COVID-19-related support and education.

Surveys offered a window into potentially effective approaches for scaled and targeted health messaging. Respondents most frequently cited media sources as their primary means for receiving COVID-19 related health information. However, they reported healthcare and local community-based resources as their most trusted sources of COVID-19 information. Social media pages with content informed by local clinicians, health professionals, and community leaders could minimize ambiguity of health messaging, facilitate accurate risk appraisal, inform protective behaviors, and allow for more trusted engagement with this population [33-35]. 
In addition to offering strategies for outreach, survey findings illuminate specific areas for improved education related to supporting appropriate risk appraisal, debunking myths, and enhancing protective behaviors. For example, the vast majority of household representatives did not perceive their households as high risk despite many having large household sizes and members working in high-risk settings. The misinformation and education gaps discovered through surveys must ultimately be considered in the context educational attainment. In this study, $41.2 \%$ of adults had either no formal education or completed primary school only. Accordingly, educational interventions can be tailored to meet the needs of individual households through collaboration with health navigators.

\section{Community empowerment and social supports}

Widespread loss, grief, and loneliness, layered with challenges to the stability of livelihoods and social networks, are just a few of the insults to mental health and wellbeing that persist amidst the COVID-19 pandemic and its resulting social and economic upheaval [2,8,36-40]. This study found that COVID-19 has impacted multiple psychosocial pathways, including household emotional health, financial security, and children's education. Over $60 \%$ of survey respondents reported increased concern within each of the 6 concern-categories explored. While this may be an appropriate and informed response amongst a pandemic, refugee and non-refugee immigrant individuals experience a disproportionately high prevalence of traumatic events in their lifetimes and the pandemic has the potential to compound psychosocial stress [41-46]. These findings highlight the need to incorporate exploration of the psychosocial impacts of the pandemic in future studies and health-promoting interventions [47].

Given its positive influence on health and wellbeing, the value of strengthening social supports should not be understated [48]. This public health intervention increased participants' engagement with respected community resources and local healthcare workers during challenging times. Re-purposing community health navigators to focus on debunking COVID-19 myths, promoting public health education, and offering free household COVID screening opened doors to conversations previously hidden behind stigma, poor understanding, and shame. Connection to community resources also enabled delivery of food boxes, cleaning supplies, face masks and other social supports like employment, health, and school tutoring services, to families isolated by language and technology barriers. The team observed a shift in community confidence over the study period of 3 months, when on multiple occasions families who presented for initial testing with one household member later returned with remaining members and neighbors.

Social support, a known resilience-promoting factor, likely enhances the baseline resilience, resourcefulness, and capacity for adversity-activated growth that is well-documented within the refugee and non-refugee immigrant community - thereby promoting improvements in health and well-being during these unprecedented times [37,38,48-51].

\section{Next Steps}

Moving forward, this community-clinical partnership will shift efforts toward community resilience in the face of ongoing pandemic threat. Semi-structured interviews, aimed at understanding the community's evolving COVID-19-related needs and perceptions, will occur with refugee community members, leaders, health navigators, and other stakeholders. Actionable insight will guide iterative evaluation and adaptation of interventions to address community needs. COVID-19 surveillance and public health education outreach will continue.

\section{Limitations}

It is possible that survey responses, particularly those related to COVID-19 related behavior, activities, and knowledge, were affected by framing and confirmation, attribution, and social desirability biases. Minimization of biases was attempted by administering surveys through trusted and trained community members, asking mostly open-ended questions, and urging interviewers to avoid providing examples for questions. Self-selection bias must also be considered when interpreting both COVID-19 screening results 
and survey findings. This study offered a free service for a historically disadvantaged and underserved population, hence randomizing and controlling enrollment was not within the study intent. Thus, it is possible those that voluntarily enrolled had a more advanced COVID-19 knowledge base, had increased level of COVID-19 related concern, and practiced more precautionary measures compared to their uninterested counterparts.

\section{Conclusion}

SUNY partnership with resettlement agencies and health navigators has greatly facilitated public health outreach grounded in community empowerment. Our interdisciplinary team provided non-invasive, voluntary, and free COVID-19 screening to a traditionally hard-to-reach refugee and non-refugee immigrant population. By engaging in open-dialogue and surveys, we assessed beliefs about COVID-19, reinforced positive behaviors, identified commonly held misconceptions, and devised targeted outreach strategies to address them. These findings are pivotal moving forward in the fight against COVID-19, especially as we aim to understand and maximize community resilience, protective behaviors and vaccine readiness and delivery.

\section{Declarations}

Funding: Funds were provided by SUNY Upstate Medical University's Institute for Global Health and Translational Science to support the costs of saliva swabs and PCR analyses.

Acknowledgements: This project would not have been possible without the exceptional support of our community partners, Catholic Charities and Interfaith Works, with their extensive support teams and refugee health navigators, including Ammar Mahmood, Roula Jneid, Mudey Omar, Catherine Holmes, Caroline Tihanyi, Dan Majewski, Lydia Andrews, Deborah Virgo, Eh Dar Bu Soe, Espoir Kimaze, Justine Nshombo, Kyaw Kyaw, Elizabeth Causgrove, Lieve Kitsa, Mustafa Aslam, Somayyeh Alizadeh, Saron Fitwi, Helen Malina, Genevieve Marshall and Olive Sephuma. We gratefully acknowledge Dr. Rachel Fabi for her support in survey development, and Dr. Frank Middleton, Rhianna Taylor, Karen Gentile and the entire team from SUNY Upstate Molecular Analysis Core Facility and Quadrant Biosciences, Inc., for their role in the development and deployment of the COVID-19 saliva swab diagnostic tool, RT-PCR analysis and diagnostic results. Finally, sincerest thanks to the participating members of the Syracuse community without which this work would not have been possible.

Competing interests: The authors declare no competing interests.

\section{References}

1. Garcini LM, Domenech Rodríguez MM, Mercado A, Paris M. A Tale of Two Crises: The Compounded Effect of COVID-19 and Anti-Immigration Policy in the United States. Psychol Trauma Theory, Res Pract Policy. 2020;12:2019-21.

2. Devakumar D, Shannon G, Bhopal SS, Abubakar I. Racism and discrimination in COVID-19 responses. Lancet [Internet]. Elsevier Ltd; 2020;395:1194. Available from: http://dx.doi.org/10.1016/S0140-6736(20)30792-3

3. Efird JT, Bith-Melander P. Refugee health: An ongoing commitment and challenge. Int J Environ Res Public Health. 2018;15:10-2.

4. Khullar D, Chokshi DA. Challenges for immigrant health in the USA-the road to crisis. Lancet [Internet]. Elsevier Ltd; 2019;393:2168-74. Available from: http://dx.doi.org/10.1016/S0140-6736(19)30035-2

5. Riggs E, Yelland J, Duell-Piening P, Brown SJ. Improving health literacy in refugee populations. Med J Aust. 2016;204:9-11.

6. Shadmi E, Chen Y, Dourado I, Faran-Perach I, Furler J, Hangoma P, et al. Health equity and COVID-19: global perspectives. Int J Equity Health. International Journal for Equity in Health; 2020;19:104.

7. National Center for Immunization and Respiratory Diseases (NCIRD) | Division of Viral Diseases. Health Equity Considerations and Racial and Ethnic Minority Groups [Internet]. cdc.gov. 2020 [cited 2020 Sep 24]. Available from: https://www.cdc.gov/coronavirus/2019-ncov/community/health-equity/race-ethnicity.html? 
CDC_AA_refVal=https\%3A\%2F\%2Fwww.cdc.gov\%2Fcoronavirus\%2F2019-ncov\%2Fneed-extra-precautions\%2Fracial-ethnicminorities.html

8. Sneed RS, Key K, Bailey S, Johnson-Lawrence V. Social and Psychological Consequences of the Covid-19 Pandemic in AfricanAmerican Communities: Lessons From Michigan. Psychol Trauma Theory, Res Pract Policy. 2020;12:446-8.

9. Oppel RAJ, Gebeloff R, Lai KKR, Wright W, Smith M. The Fullest Look Yet at the Racial Inequity of Coronavirus. New York Times [Internet]. 2020 Jul 5; Available from: https://www.nytimes.com/interactive/2020/07/05/us/coronavirus-latinosafrican-americans-cdc-data.html

10. Fortuna LR, Tolou-Shams M, Robles-Ramamurthy B, Porche M V. Inequity and the Disproportionate Impact of COVID-19 on Communities of Color in the United States: The Need for a Trauma-Informed Social Justice Response. Psychol Trauma Theory, Res Pract Policy. 2020;12:443-5.

11. Centers for Disease Control and Prevention (CDC). COVID-19 in Newly Resettled Refugee Populations [Internet]. cdc.gov. 2020 [cited 2020 Aug 4]. Available from: https://www.cdc.gov/coronavirus/2019-ncov/need-extra-precautions/refugeepopulations.html

12. Rees S, Fisher J. COVID-19 and the Mental Health of People From Refugee Backgrounds. Int. J. Heal. Serv. 2020.

13. Refugee Resettlement in U.S. Cities [Internet]. New Am. Econ. Res. Fund. 2019 [cited 2020 Feb 20]. Available from: https://data.newamericaneconomy.org/en/refugee-resettlement-us/\#exploratory_tool

14. United States Census Bureau. Syracuse, New York [Internet]. 2018 [cited 2020 Feb 21]. Available from: https://www.census.gov/quickfacts/fact/table/syracusecitynewyork/RHI125218\#RHI125218

15. CNYVitals. How the History of Redlining and I-81 Contributed to Syracuse Poverty [Internet]. 2018 [cited 2020 Apr 14]. Available from: https://cnyvitals.org/how-the-history-of-redlining-and-i-81-contributed-to-syracuse-poverty/.

16. HealtheCNY. Community Dashboard | Disparities Data | Onondaga [Internet]. HealtheCNY.org. 2020 [cited 2020 Oct 1]. Available from: http://www.healthecny.org/index.php? module=indicators\&controller=index\&action=dashboard\&alias=disparities

17. Kneebone E, Holmes N. U.S. concentrated poverty in the wake of the Great Recession [Internet]. Brookings. 2016 [cited 2020 Aug 4]. Available from: https://www.brookings.edu/research/u-s-concentrated-poverty-in-the-wake-of-the-great-recession/

18. Onondaga County Health Department. COVID-19 Data and Reports [Internet]. ongov.net. 2020 [cited 2020 Oct 1]. Available from: https://covid19.ongov.net/data/

19. Coin G. Utica embraces its refugees, but they're bearing the brunt of coronavirus [Internet]. syracuse.com. 2020 [cited 2020 Oct 1]. Available from: https://www.syracuse.com/coronavirus/2020/07/utica-embraces-its-refugees-but-theyre-bearing-the-bruntof-coronavirus.html

20. Eisenstadt M. Inside Green Empire Farm: Upstate NY's biggest coronavirus outbreak slams migrant workers [Internet]. syracuse.com. 2020 [cited 2020 Oct 1]. Available from: https://www.syracuse.com/coronavirus/2020/05/inside-green-empirefarm-upstate-nys-biggest-coronavirus-outbreak-slams-migrant-workers.html

21. InterFaith Works. COVID-19 | Let's Protect our Community. Syracuse; 2020.

22. Huynh N. Coronavirus: Helping and informing people with a language barrier [Internet]. syracuse.com. 2020 [cited 2020 Oct 1]. Available from: https://www.syracuse.com/coronavirus/2020/04/coronavirus-how-to-help-and-inform-people-with-a-languagebarrier.html

23. Balcazar H, Lee Rosenthal E, Nell Brownstein J, Rush CH, Matos S, Hernandez L. Community health workers can be a public health force for change in the United States: Three actions for a new paradigm. Am J Public Health. 2011;101:2199-203.

24. Hartzler AL, Tuzzio L, Hsu C, Wagner EH. Roles and functions of community health workers in primary care. Ann Fam Med. 2018;16:240-5.

25. Lohr AM, Ingram M, Nuñez A V, Reinschmidt KM, Carvajal SC. Community-Clinical Linkages with Community Health Workers in the United States: A Scoping Review. Physiol Behav. 2018;19:349-60.

26. Peretz PJ, Islam N, Matiz LA. Community Health Workers and Covid-19 - Addressing Social Determinants of Health in Times of Crisis and Beyond. N Engl J Med [Internet]. 2020;1-2. Available from: nejm.org 
27. Quadrant Biosciences. The Clarifi COVID-19 Test Kit from SUNY Upstate and Quadrant Biosciences [Internet]. 2020 [cited 2020 Sep 28]. Available from: https://www.quadrantbiosciences.com/covid-19-projects/

28. Quadrant Biosciences. How To Swab [Internet]. 2020 [cited 2020 Sep 28]. Available from: https://vimeo.com/447268833

29. DNA Genotek. Superior samples • Proven performance Inactivation of SARS-CoV-2 in samples collected using Oragene ${ }^{\circledR}$, ORAcollect ${ }^{\circledR}$ and OMNIgene® products from DNA Genotek ${ }^{\mathrm{TM}}$ [Internet]. 2020 [cited 2020 Oct 1]. Available from: www.dnagenotek.com

30. Mulder JT. Covid-19 cases plunge in Onondaga County; 'We've starved the virus' - syracuse.com [Internet]. syracuse.com. 2020 [cited 2020 Oct 1]. Available from: https://www.syracuse.com/coronavirus/2020/08/covid-19-cases-plunge-in-onondagacounty-weve-starved-the-virus.html

31. Allen P, Breidenbach M. Refugees in Onondaga County: Where are they from? When did they arrive? [Internet]. syracuse.com. 2017 [cited 2020 Oct 1]. Available from: https://www.syracuse.com/news/2017/02/refugees_in_onondaga_county_where_are_they_from_when_did_they_arrive_1.html

32. Miner SA, Driscoll PS. City of Syracuse Department of Neighborhood and Business Development I Third Annual Action Plan, Program Year 38 (2012-2013). Syracuse; 2011.

33. Ngai CSB, Singh RG, Lu W, Koon AC. Grappling With the COVID-19 Health Crisis: Content Analysis of Communication Strategies and Their Effects on Public Engagement on Social Media. J Med Internet Res. 2020;22:e21360.

34. González-Padilla DA, Tortolero-Blanco L. Social media influence in the COVID-19 pandemic. Int Braz J Urol. 2020;46:120-4.

35. Garfin DR, Silver RC, Holman EA. The novel coronavirus (COVID-2019) outbreak: Amplification of public health consequences by media exposure. Heal Psychol. 2020;39:355-7.

36. Crayne MP. The Traumatic Impact of Job Loss and Job Search in the Aftermath of COVID-19. Psychol Trauma Theory, Res Pract Policy. 2020;12:180-2.

37. Duane AM, Stokes KL, DeAngelis CL, Bocknek EL. Collective Trauma and Community Support: Lessons From Detroit. Psychol Trauma Theory, Res Pract Policy. 2020;12:452-4.

38. Zhai Y, Du X. Loss and grief amidst COVID-19: A path to adaptation and resilience. Brain , Behav , Immun. 2020;

39. Killgore WD, Cloonan SA, Taylor EC, Dailey NS. Loneliness: A signature mental health concern in the era of COVID-19. Psychiatry Res. 2020;

40. Torales J, O'Higgins M, Castaldelli-Maia JM, Ventriglio A. The outbreak of COVID-19 coronavirus and its impact on global mental health. Int J Soc Psychiatry. 2020;66:317-20.

41. Giacco D, Laxhman N, Priebe S. Prevalence of and risk factors for mental disorders in refugees. Semin Cell Dev Biol [Internet]. Elsevier Ltd; 2018;77:144-52. Available from: https://doi.org/10.1016/j.semcdb.2017.11.030

42. Hameed S, Sadiq A, Din AU. The Increased Vulnerability of Refugee Population to Mental Health Disorders. Kansas J Med. 2019;11:20-3.

43. Mattar S, Piwowarczyk LA. COVID-19 and U . S . -Based Refugee Populations: Commentary. 2020;12:228-9.

44. Steel Z, Chey T, Marnane C, Bryant RA, Ommeren M Van. Association of Torture and Other Potentially Traumatic Events WithMental Health Outcomes Among Populations Exposed toMass Conflict and Displacement. JAMA Psychiatry. 2015;302:537-49.

45. Venkateswaran KD, Hauser CT. Living With PTSD Amid a Global Pandemic. Psychol Trauma Theory, Res Pract Policy. 2020;12:71-2.

46. Fazel M, Wheeler J, Danesh J. Prevalence of serious mental disorder in 7000 refugees resettled in western countries: A systematic review. Lancet. 2005;365:1309-14.

47. Lei MK, Klopack ET. Social and Psychological Consequences of the COVID-19 Outbreak: The Experiences of Taiwan and Hong Kong. Psychol Trauma Theory, Res Pract Policy. 2020;12:35-7.

48. Duden GS, Martins-Borges L, Rassmann M, Kluge U, Willecke TG, Rogner J. A qualitative evidence synthesis of refugee patients' and professionals' perspectives on mental health support. Community Psychol Glob Perspect. 2020;6:76-100.

49. Grandi $F$ (UNHCR). What we can learn from refugees in the fight against COVID-19 [Internet]. World Econ. Forum. 2020 [cited 2020 Oct 1]. Available from: https://www.weforum.org/agenda/2020/06/refugees-covid19-unhcr-what-we-can-learn/ 
50. Papadopoulos RK. Refugees, trauma and Adversity-Activated Development. Eur J Psychother Couns. 2007;9:301-12.

51. Ssenyonga J, Owens V, Olema DK. Posttraumatic Growth, Resilience, and Posttraumatic Stress Disorder (PTSD) among Refugees. Procedia - Soc Behav Sci [Internet]. Elsevier B.V.; 2013;82:144-8. Available from:

http://dx.doi.org/10.1016/j.sbspro.2013.06.238

\section{Tables}

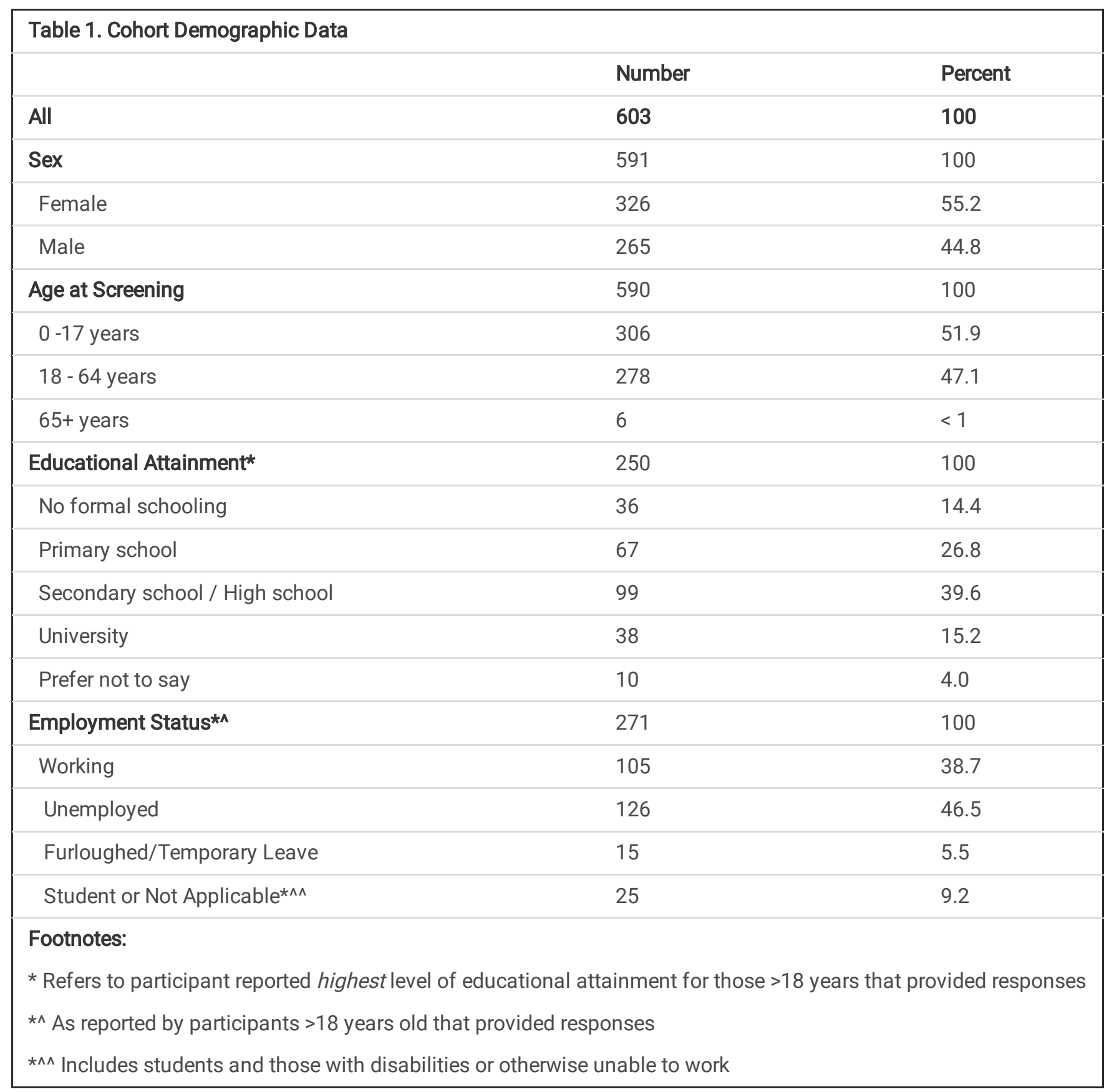


Table 2. Risk Perceptions

\begin{tabular}{|c|c|c|}
\hline & Number & Percent \\
\hline All & 188 & 100 \\
\hline Do you consider your household high risk for COVID-19? & 184 & 100 \\
\hline Yes & 27 & 14.7 \\
\hline No & 157 & 85.3 \\
\hline Why do you consider your household high risk for COVID-19?* & 27 & 100 \\
\hline Household member(s) works outside the home & 10 & 37.0 \\
\hline Confirmed infection in household & 1 & 3.7 \\
\hline Suspected infection in household & 1 & 3.7 \\
\hline Children attend school or daycare program & 0 & 0 \\
\hline Pre-existing condition in self or household member & 5 & 18.5 \\
\hline Other** & 13 & 48.1 \\
\hline Where in Syracuse do you think your family is at most risk for getting COVID-19?* & 188 & 100 \\
\hline Home & 0 & 0 \\
\hline Work & 31 & 16.5 \\
\hline Grocery store & 97 & 51.6 \\
\hline Place of worship & 12 & 6.4 \\
\hline School & 20 & 10.6 \\
\hline Parks & 10 & 5.3 \\
\hline Hospitals or clinics & 23 & 12.2 \\
\hline "Crowded places" "Groups of people" & 20 & 10.6 \\
\hline "Everywhere" & 9 & 4.8 \\
\hline I don't know & 20 & 10.6 \\
\hline Other*^ & 44 & 23.4 \\
\hline
\end{tabular}

\section{Footnotes:}

* Asked as open-ended questions and responses coded to pre-determined categories; Multiple responses accepted per household representative.

**Examples of "other" responses include: "My house was burnt down and I am living in someone's house whereby we are all fixed in it," and "Because when anyone in the family went out for grocery stores can bring the virus."

*^ Examples of "other" responses include: "we stay indoors and don't go out that much," "outside of home," and "downtown"

Table 3. Household Behaviors \& Activities

\begin{tabular}{|lll|}
\hline All & Number & Percent \\
\hline Household precautions* & 188 & 100 \\
\hline
\end{tabular}




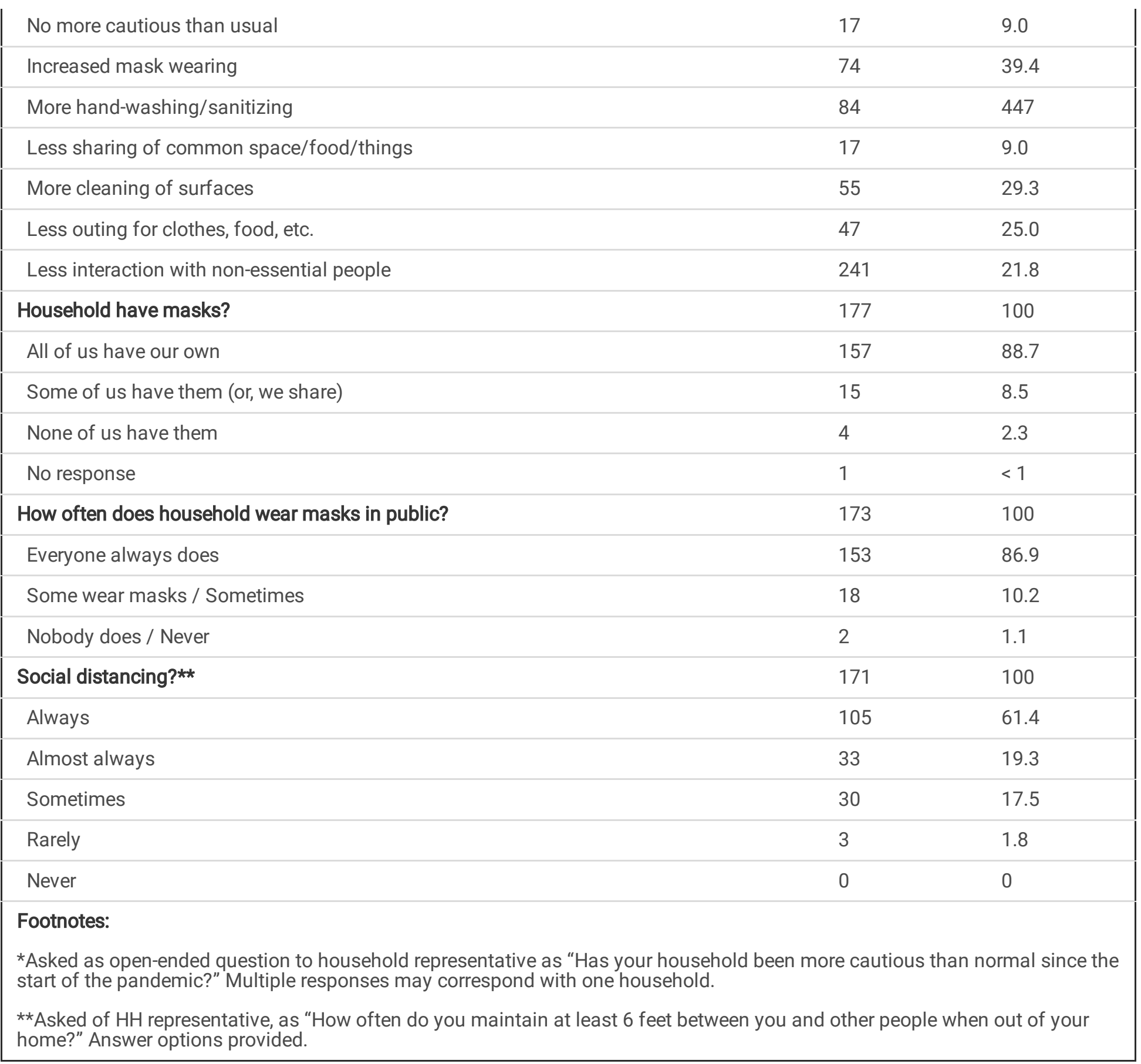




\section{Table 4. Health Communications}

\begin{tabular}{|c|c|c|}
\hline & Number & Percent \\
\hline All & 106 & 100 \\
\hline How do you and your household normally get your health information?* & 106 & 100 \\
\hline News outlets & 45 & 42.5 \\
\hline CDC or WHO news/updates & 1 & $<1$ \\
\hline Social media & 39 & 36.8 \\
\hline My doctor/ doctor's office & 14 & 13.2 \\
\hline Doctors, generally & 6 & 5.7 \\
\hline Health navigator or case manager & 5 & 4.7 \\
\hline CYO & 15 & 14.2 \\
\hline Friends or family & 18 & 17.0 \\
\hline Television & 29 & 23.08 \\
\hline Hospital & 16 & 15.1 \\
\hline Other** & 23 & 21.7 \\
\hline No response & 1 & $<1$ \\
\hline Who do you trust most when it comes to information about COVID-19?* & 106 & 100 \\
\hline News outlets & 16 & 15.1 \\
\hline CDC or WHO news/updates & 4 & 3.8 \\
\hline Social media & 7 & 6.6 \\
\hline My doctor/ doctor's office & 18 & 17.0 \\
\hline Doctors, generally & 34 & 32.1 \\
\hline Health navigator or case manager & 8 & 7.5 \\
\hline CYO & 17 & 16.0 \\
\hline Friends or family & 1 & $<1$ \\
\hline Television & 6 & 5.7 \\
\hline Hospital & 6 & 5.7 \\
\hline Other*^ & 32 & 30.2 \\
\hline No response & 3 & 2.8 \\
\hline \multicolumn{3}{|l|}{ Footnotes: } \\
\hline \multicolumn{3}{|c|}{$\begin{array}{l}\text { *Asked as open-ended questions; responses coded to pre-determined categories. Multiple responses accepted per householc } \\
\text { representative. }\end{array}$} \\
\hline \multicolumn{3}{|c|}{ **Common "Other" responses include: "job/co-workers," and "the community/community leaders" } \\
\hline \multicolumn{3}{|c|}{${ }^{\star \wedge}$ Common "Other" responses included: "my teachers in school," the community, and nurses/healthcare workers } \\
\hline
\end{tabular}

\section{Figures}


27 Countries of Origin $(\mathbf{N}=\mathbf{1 8 8})$

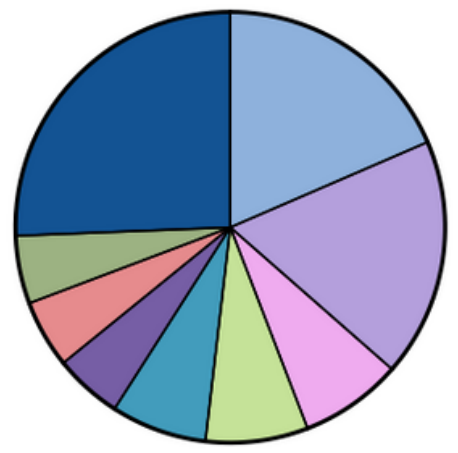

22 Primary Spoken Languages $(\mathrm{N}=187)$

Burma (18.5\%)

$\operatorname{DRC}(17.9 \%)$

Congo $(7.7 \%)$

Eritrea $(7.7 \%)$

Somalia $(7.2 \%)$

$\operatorname{Iraq}(5.1 \%)$

Sudan $(5.1 \%)$

Syria $(5.1 \%)$

Other* $(25.6 \%)$

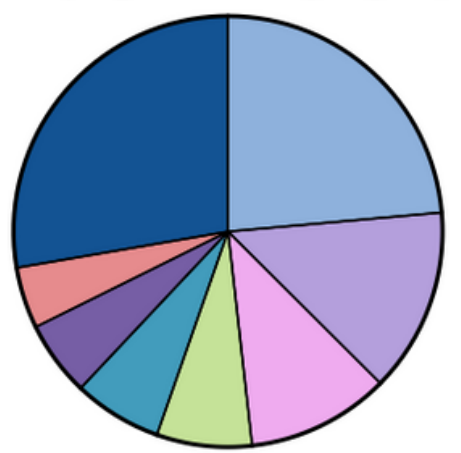

Swahili (23.6\%)

Arabic (13.9\%)

Karen $(10.8 \%)$

Somali $(7.2 \%)$

Tigrinya $(6.7 \%)$

Burmese (5.6\%)

Nepali $(4.6 \%)$

Other** $(27.7 \%)$

Figure 1

Household-level demographics were reported from N=188 households ( $96.4 \%$ of total) and $\mathrm{N}=187$ households $(95.9 \%$ of total). ${ }^{*}$ Other countries include Afghanistan, Bhutan, Burundi, Central African Republic, Guatemala, Iran, Kenya, Liberia, Laos, Nepal, Rwanda, Somalia, South Sudan, Sri Lanka, Uganda, Vietnam, Yemen, Cuba, and Ethiopia. ** Other languages include Amharic, Chin, Chinese, Dari, French, Fur-Arabic, Karenni, Kinyarwanda, Kirundi, Masalit, Sango, Somali, Spanish, Tamil, Vietnamese, and English.

\section{Frequency Distribution of U.S. Arrival Year}

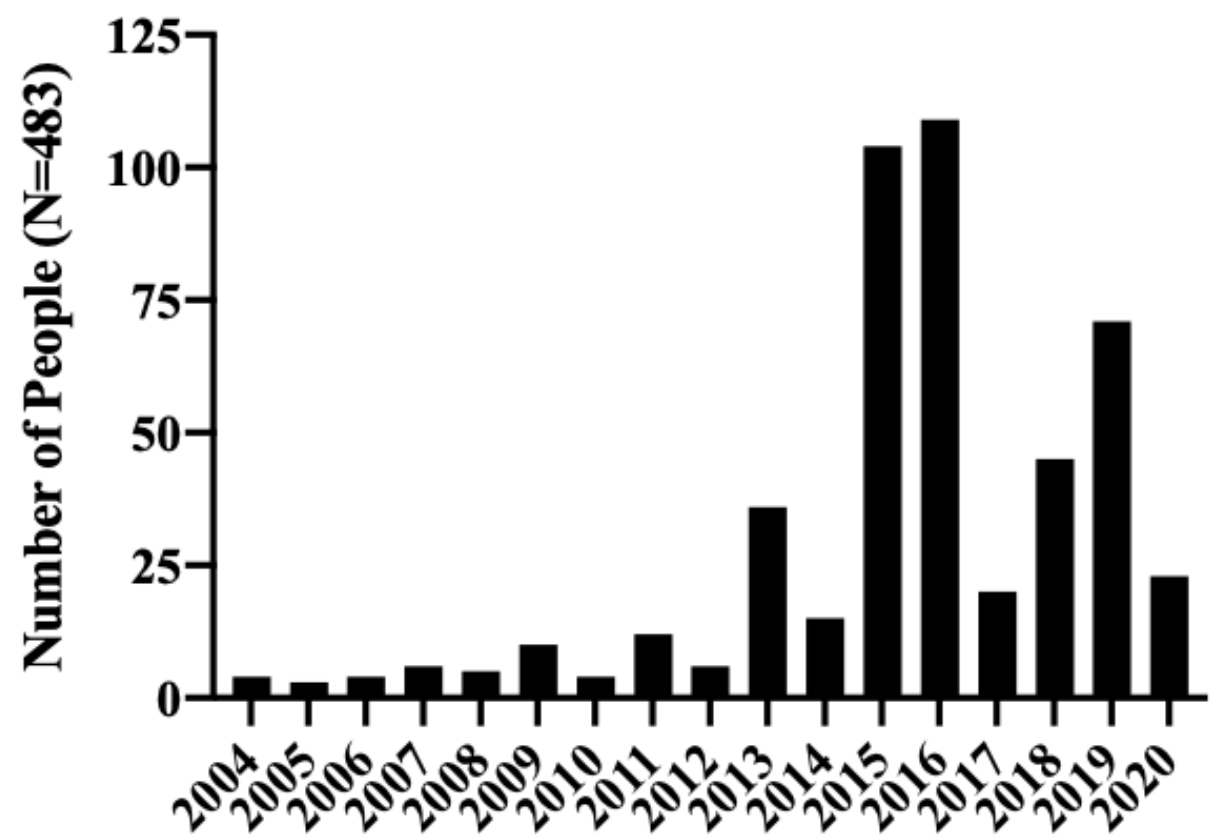

\section{U.S. Arrival Year}

Figure 2

Frequency distribution of individuals' year of arrival to the United States (U.S.). $\mathrm{N}=483$ included in analysis, which excludes individuals that arrived between $1982-2001$ ( $N=5[<1 \%$ of total cohort]) and those born in U.S. ( $N=64$ [10.6\% of overall cohort]). 


\section{Frequency Distribution of Age}

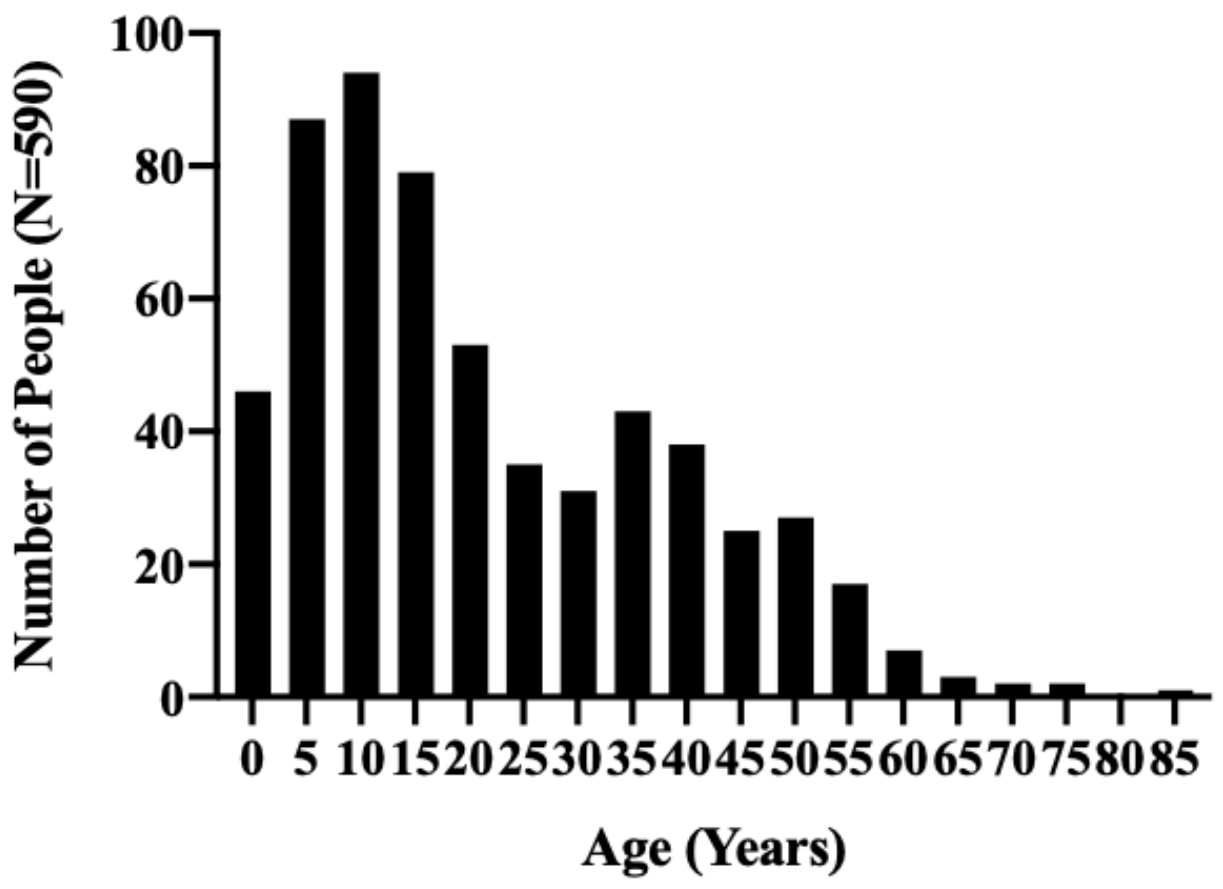

Figure 3

Frequency distribution of individuals' age. $\mathrm{N}=590$, which excludes 13 individuals for which data is missing. Median age is 17 years old (range 3 months to 85 years; IQR 8.25-35 [26.8 years]).

Concern in the Context of COVID-19 ( $N=195$ households)

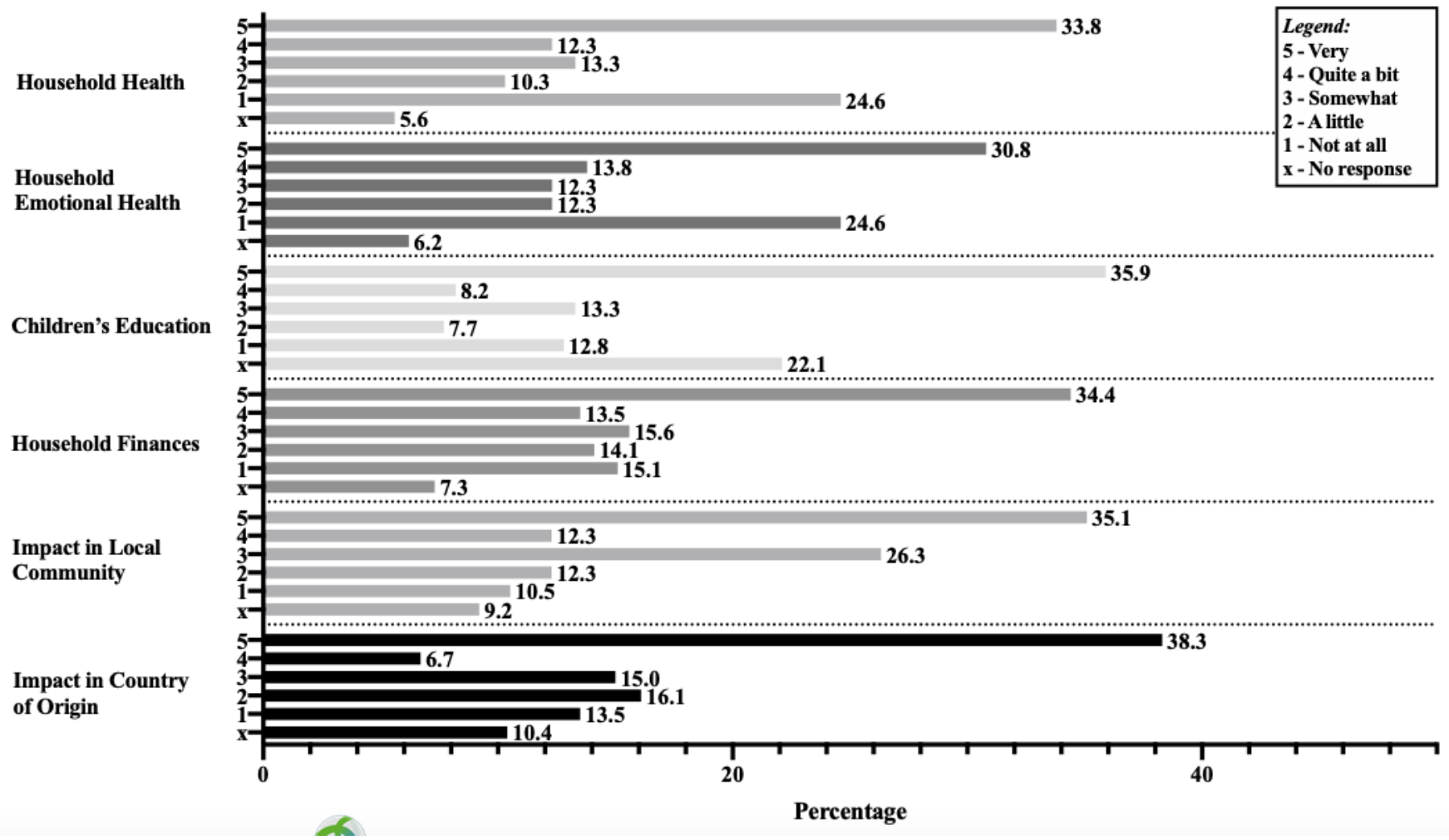


Figure 4

Concern in the context of COVID-19 was reported by 195 household representatives, on a scale of 1-5, for the 6 topics displayed on $y$-axis. Percentages of each response are displayed at the end of the respective bars. Select comments included the following: "Children were learning through computer, but it wasn't helpful because they have been asking questions and [we] are not able to give the answer because of language barrier," "Very concerned about the local community because some people are not following rules," "Very worried [about country of origin] because not enough resources," "People are very sad about COVID-19," "Very sad because everything has changed," "The children are home and we don't know how to help them," "The household is very sad," We are worried financially because we are not working and have no employment benefits," "[Concerned] because some people are not following the rules," and "Worried [about country of origin] because a lot of poverty, no income." 